\title{
Curriculum, quantitative concepts and methodology of teaching children with learning difficulties
}

\author{
Mawutor Avoke \\ Department of Special Education \\ University of Education, Winneba, Ghana
}

\begin{abstract}
The article examines some trends in curriculum development for children with learning difficulties in Ghana, drawing some comparisons from perspectives in the United Kingdom. Reference is made to a research on the institutionalisation of children with learning difficulties to illustrate the contradictions and dilemma that exist in the teaching of quantitative concept or arithmetic to children with learning difficulties in two special schools in Ghana. The article argues the need to address the learning needs of pupils with difficulties. Example of the focus of these needs are the development of quantitative concepts and survival arithmetic through differential learning experiences, while a review of methodology or approaches to teaching is underlined. It is important to reiterate that this article is part of a major study on the institutionalisation of children with mental retardation in two residential schools in Ghana, and consequently reference is made to the research study when examples are cited from schools in Ghana.
\end{abstract}

\section{Introduction}

The article maps out the trend in curriculum development in Ghana and argues that the educational reforms in Ghana did not influence curriculum development in special schools for children with learning difficulties, which resulted in a lack of adequate progress and documentation of curriculum trends in special schools for children with learning difficulties. Aspect of the curriculum relating to the teaching of quantitative concept in two schools are examined, and the point is made that many children with learning difficulties have the capacity for arithmetic of survival, but there is some concern about how it is taught. The thesis of this paper is that the teaching of arithmetic for survival or basic quantitative concepts, should be underpinned by a relevant methodology that should aim at meeting the deferential needs of the pupils in special and regular schools. The main strands of this article are as follows:

- curriculum for special schools in Ghana,

- lack of access and ownership of the curriculum .

- quantitative concept and arithmetic in special schools,

- methodology of teaching children with learning difficulties 


\section{Curriculum development}

The curriculum forms the cornerstone of successful education for all pupils, including those with special educational needs. Without a coherent and relevant curriculum the quality of education for pupils with learning difficulties will suffer (Farrell, 1997). Farrell argues that teaching techniques and approaches cannot be in a vacuum, therefore the first priority when planning teaching programmes for pupils is to decide what they should be taught. He relates that having a carefully planned and relevant curriculum should be the first priority for a school. Curriculum is however, influenced by the philosophical and educational trends and policies within specific countries and this does not seem to be the case regarding the curriculum in special schools for children with learning difficulties in Ghana.

Please see below:

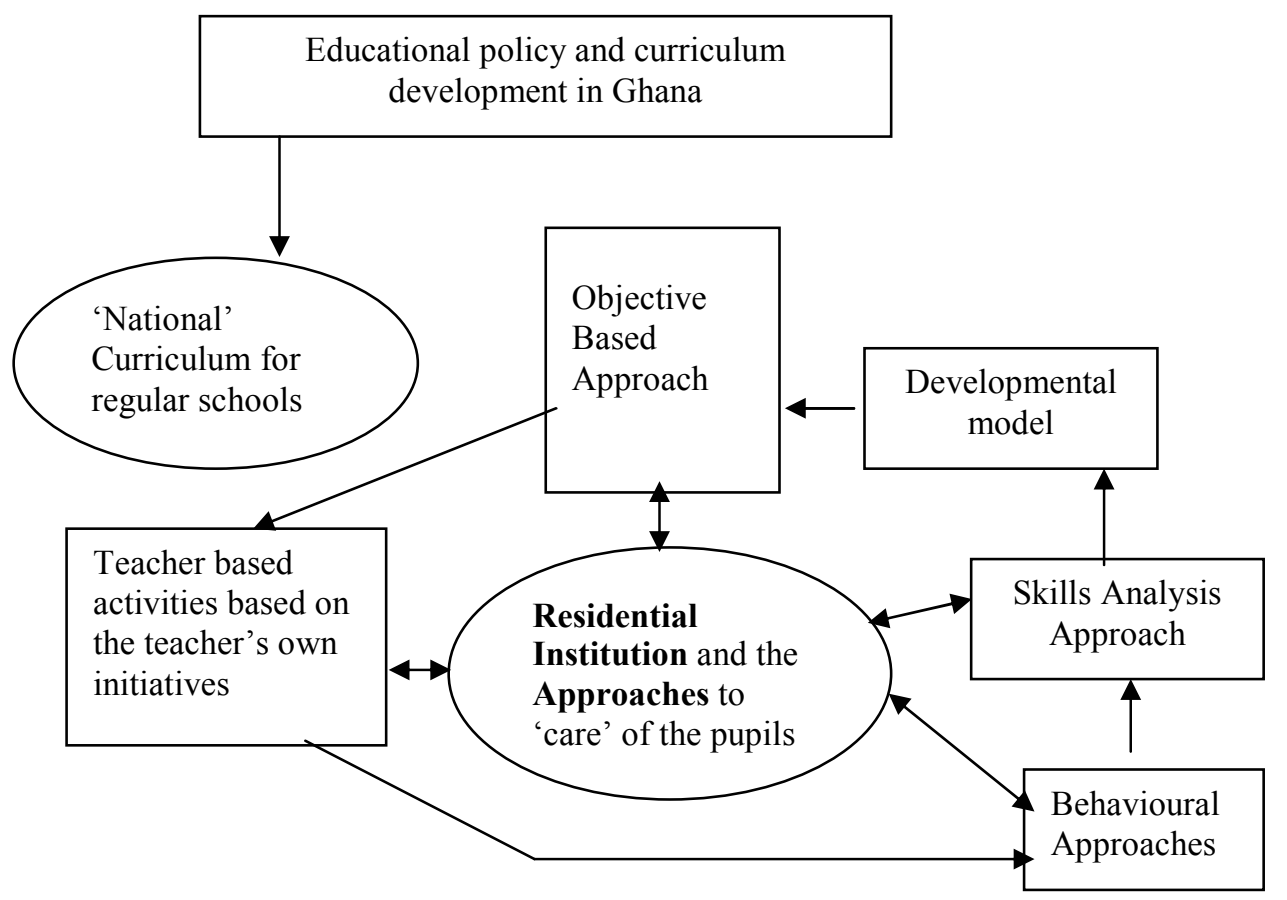

The educational reforms and curriculum restructuring in Ghana had little influences on the curriculum of residential special schools for children with intellectual difficulties in Ghana, and this is shown by the lack of a link between the educational policy and the curriculum on offer as shown in the model in Fig. 1.

From the scrutiny and observation of the curriculum documents in some special schools in Ghana, it is evident from the model that teachers developed objectives alongside the lines of specific behaviours in a similar way to the Skills Analysis Model used in the 1980s in the United Kingdom. Such a model (based on learning theories) relies on reinforcement and rewards as critical to the acquisition of skills. Teachers also made use of 
checklists which were devised to take into consideration the mental ages and developmental growth of the children in the schools.

It was apparent that the learning experiences of pupils in these schools was influenced largely by the personal theories of the teachers, resulting in a teacher-initiated approach to teaching, as shown in the Figure above. The influences on the teaching in the two schools, was eclectic and, consequently there was a lack of ownership of the existing curriculum which they had little knowledge of any way.

\section{Lack of access and ownership of the curriculum}

As already stated in the Figure above, the curriculum document was not derived from the educational reforms in Ghana despite the fact that the curriculum was developed within the same year (1987).

The lack of knowledge of their own curriculum documents by the teachers was apparent:

The school curriculum! I cannot say we really have a curriculum. What we have is something to guide our teaching per se. If I tell you I have not seen a copy of that document of a curriculum you would doubt it (Teacher, Special school, A).

We do not have any fixed curriculum even though we prepared a curriculum ten years ago in Togo, the teachers do not use it (Headmaster, Special School B).

Ironically, the (elusive) curriculum states that lessons as well as individual objectives are to be 'selected from the curriculum before teaching'. It is logical, however, that 'ownership of a curriculum is important if a school is to be effective in educating its pupils' (Sebba, Byers and Rose 1993, p.57).

The course of curriculum development for people with mental retardation in Ghana has not been as properly documented as experiences in the United Kingdom. It is therefore difficult to map out the precise developments that have taken place over the years. Clearly, while the United Kingdom, for example, has gone through many stages in the development of curriculum for all, and is now implementing one influenced by a philosophy of inclusion, curriculum in schools for children with mental retardation in Ghana continues to be at a basic stage.

When commenting on trends in the United Kingdom, however, Carpenter and Ashdown (2001) noted that the affirmation of an 'entitlement' was only a first step in the implementation of the development of a National Curriculum for all. They also acknowledged the fact that 'entitlement' was not necessarily the solution to the learning problems of children with learning difficulties. This point is supported by Ouvry and Saunders (1996), who emphasised that even though the introduction of the National Curriculum in the United Kingdom changed the focus of curriculum development towards issues of entitlement and access across curriculum subjects for all pupils: 
'Many practitioners, who work with pupils with PMLD are still striving to achieve a sufficient integration between the subject-led National Curriculum and the developmental and learning needs of these pupils' (p.202).

Ouvry and Saunders are commenting on the education of pupils with profound and multiple learning difficulties, but one specific concern of this article is the teaching of quantitative or arithmetic skills in special schools.

\section{Quantitative concept and arithmetic in special schools}

McConkey and McEvoy (1986) found that only 75 percent of 51 children with severe learning difficulties aged 12 to 18 could recognise how many were in a set under five and only 51 children could successfully name the number of objects in a set of five and ten. According to these authors, if a child is still in the piagetian pre-occupational stage, no amount of teaching will help the child understand certain relationships. They argued that the question that needs to be asked is whether or not children with severe learning difficulties should be tested on these academics target. O' Toole and O' Toole (1989) have also suggested that a more realistic goal may well be to read the street and bus numbers, tell time, recognise different coins and be able to use the telephone.

What is critical, however, is the importance of involving children in basic arithmetic to gain the experiences of relevant quantitative concepts for their day to day activities and survival. Berger, Morris and Portman (2000) argued that teachers should involve all pupils in arithmetic lessons and ensure where possible that lessons are appropriately differentiated to cater for the needs of all, and (Germain, 2001) comments that such a trend poses a challenge to primary teachers when increasing numbers of pupils with moderate or severe learning difficulties are being included in the mainstream schools. Hanrachan and Newman (1996) acknowledged that even though there have been few investigation designed specially to look at mathematics achievement of pupils with Down syndrome, the situation has begun to change with the realisation that many pupils with Downs syndrome can understand mathematical concepts. Lorenz's (1999) work relating to the teaching of basic mathematics skills to children with Down's syndrome is worthy of note, and Germain (2001) citing Caycho, Gunn and Siegal (1991) demonstrates that children with Down's Syndrome appear to develop mathematical concepts in the same way as non handicapped children.

Skarkey and Gelman (1982) showed that children, aged between three and five years, were able to solve simple addition and subtraction problems, involving small numbers when they were asked to work out how many pennies an adult had in his hand. By using their fingers to represent the hidden objects, or counting aloud, they were able to solve the problems. The basic approach in teaching these skills to children with learning difficulties may vary from those pertaining to non handicapped children, and thus Germain (2001) citing Lovenz (1998) warned that teachers should be encouraged to differentiate work appropriately and include pupils with learning difficulties in the whole class teaching. 
In research conducted by the author of this article, teachers' expressed concern that the 'curriculum' or programme of study in the schools involved in that study generally had a strong leaning towards the teaching of 'academic' skills.

The present curriculum orientation looks too bookish for my liking. That is what I have realised (Teacher, Special School, A).

I cannot say we are covering even $20 \%$ of the curriculum because most of the activities are more academic. There is too much teaching of abstract arithmetic, which makes it difficult (Teacher, Special School B).

The emphasis on the academic skill component of the curriculum in the schools for children with learning difficulties was evident in the focus group discussion with the pupils, and teachers in two residential special schools. In that study referred to in the preceding paragraph, the author used participant observation, interviews-focus group and one on one, and document scrutiny, as the main methods of inquiry. When asked what the pupils were usually taught at school, they stated that:

Everyday it is ' 1, 2, 3, 4 that is what the teachers teach every day (Pupils Focus Group, Special School, B).

Moths and English (Pupils Focus Group, Special School B).

I am in the educable class, group 4. We draw triangle and rectangle and everything we like (Pupils Focus Group, Special School, A).

Clearly the pupils were indicating that there was a strong emphasis on mathematics. Interestingly, the Inspection Report on School, A in 1995 by the Special Education Directorate noted that:

'Mentally handicapped children in the educable category are able to perform at sixth grade level' (Inspection Report Special School A, 1995 p.15).

What this statement suggests is that children with 'mild learning difficulties' within that school were performing at primary six level in the regular school. Such comments were taken to be a compliment to the schools' efforts in emphasizing arithmetic in these schools.

In an examination of the schools' Inspection Report, it was noted pupils at the educable level could perform at sixth grade level, which raises the questions of why they could not be included in regular classes.

Indeed, one teacher at School A commented that:

It would appear that most people feel that the trainable and educable should proceed after sometime to the mainstream. This is perhaps another justification for the bookish approach. Look at the type of mathematics they are taught (Teacher, Special School A).

If such a comment was meant to justify the adoption of teaching strategies that promoted specific school subjects such as arithmetic, why then were the teachers complaining that the curriculum or the programmes of study in the schools were too 'academic' or 'bookish'? 
In the major study referred to in preceding pages, large number of lessons were observed. In one of the lessons, the short-term objective was stated as: 'the children should be able to identify the various shapes from objects put together'. This objective was set for a class of ten pupils, and throughout the entire lesson the teacher's medium of communication was the English language, an unfortunate choice as English was not first language of these pupils. At the time of the study, it used to be a basic requirement of the Ghana Education service that teachers should be encouraged to use the local languages during the first three years of primary school. In many special schools for children with learning difficulties in Ghana, however, the first language continues to be recognised as the medium of instruction. The consequence of the use of English for many of these children was that the quantitative concepts and other learning experiences they were introduced to invariably became meaningless, owing to the fact that the concepts are not made relevant to the pupils by teachers who should be facilitating these experiences. This apparent lack of relevance is even more serious within the mainstream and other integrated settings when children with difficulties are placed there.

Clearly some children with learning difficulties may have cognitive difficulties that could slow the general process of conceptualising aspects of these quantitative concept, which makes the methodology of teaching them an important aspect of the teaching and learning process.

\section{Methodology of teaching children with learning difficulties}

According to Rose (1998)

'Many of the arguments which have surrounded the relevance, or otherwise, of the National Curriculum have focused upon content and have chosen to ignore the issue of learning and pedagogy' (Rose, p.30).

Rose's point is particularly pertinent in the Ghanaian context, as methodology that is used to teach such children with learning difficulties is central to finding some of the solutions to their learning problems. Within Ghana, for example, a study was conducted by the National Programme of Action on Basic Education in 1994, which revealed that the basic schools in Ghana, (which will primary one to secondary school year eight in the UK) were generally unable to provide minimal levels of learning to the majority of the pupils. This point makes the argument about methodology very relevant.

When commenting on the National Curriculum within the United Kingdom authors such as Aird, (2001) suggested that the:

'Bulk of the National Curriculum was largely irrelevant and meaningless to the circumstances of many pupils with SLD/PMLD' (Aird 2001, p.1).

According to this author, the curriculum material was pitched above the ability of many of the pupils and the pace of learning was too extensive to allow for the relatively modest attainments that pupil with severe learning difficulties would make. In his opinion, teachers in schools catering for 
pupils with severe learning difficulties in the United Kingdom during the 1990s were guilty of compromising the needs of their pupils in their struggle to implement the National Curriculum. Such a trend according to Aird (2001) could be described as the corporate guilt of teachers arising out of the desire to uphold the rights of entitlement of their pupils at all cost, even though they were aware of the short-comings of that entitlement.

The apparent inherent inadequacies within the National Curriculum in that country ultimately prompted the need for further review of the curriculum in order to guarantee access for all. Thus, Carpenter and Ashdown (2001) comment that it is because of the inequalities of entitlement that the debate on the curriculum moved to access. Clearly the new curriculum document brought out in 2001, (DfEE/QCA 2001) was concerned with inclusion and special needs. An inclusive curriculum invariably requires that an approach to delivering the curriculum in such a way that the learning needs of pupils is met within that context.

The importance of methodology in facilitating the delivery of the curriculum cannot be over emphasised. In the research on institutionalisation of children with learning difficulties in the two schools in Ghana, observation of the lessons in both schools showed that it was not so much what the pupils were taught that made the subjects or skills 'academic'. The concerns regarding arithmetic, in my opinion, were largely influenced by the method of delivery of the curriculum. Teachers were giving a free choice in selecting what they wanted to teach, and accordingly prepared their own lesson notes, forecasts and schemes of work. Even though the curriculum appeared to be illusive, for reasons already outlined, the presentation of the learning experiences was the main source of tension and which led to the lack of progress.

\section{Conclusion}

From this discussion, it is important to acknowledge the usefulness of arithmetic and other quantitative concept as a means of introducing children with learning difficulties to basic survival skills. However, in order that effective learning takes place, it will be important that teachers appreciate the differences in learning styles of these pupils. It will also be important for them to encourage the differentiation of task in order to promote the learning experiences of children with learning difficulties within the context on the curriculum that is on offer in schools. Such an initiative will require a critical examination of methodology and style of teaching in regular and special schools within Ghana. 


\section{References}

Aird, R. (2001) The Education and Care of Children with Severe, Profound and Multiple Learning Difficulties. London: David Fulton.

Berger, A., Morris, D., and Portman, J. (2000) Implementing the National Numeracy Strategy for pupils with Learning Difficulties-Access to the daily Mathematics Lesson. London: David Fulton.

Carpenter, B. \& Ashdown, R. (2001) 'Enabling access', in B. Carpenter, K. Ashdown \& K. Bovair (eds.) Enabling Access: Effective Teaching and Learning for Pupils with Learning Difficulties. London: David Fulton.

Department for Education and Skills (DfES) (2001) Special Educational Needs: Code of Practice. London: HMSO.

Farrell, P. (1997) Teaching Pupils with Learning Difficulties: Strategies and Solution. London: Cassell

Germain, R (2001) Access to Numeracy: A case study. British Journal of Special Education, 28 (4), 182-186.

Hanrachan, J. and Newman, J. (1996) 'Teaching addition to children'; in B. Straford and P. Gunn (ed.) New approaches to Down's Syndrome. London: Cassell

Lorenz, S (1999) 'Thinking figures'. Special. Spring, 30-31.

McConkey, R. and McEvoy, J. (1986) 'Games for learning to count'. British Journal of Special Education, 1, 13-22.

National Programme of Action (1994) The National Programme of Action on Basic Education. Accra: Ministry of Education.

O' Toole, B and O' Toole, P (1989) 'From counting to arithmetic'. British Journal of Special Education, 16 (3),115-117

Ouvry, C. \& Saunders, S. (1996) 'Pupils with profound and multiple learning difficulties', In: B. Carpenter, R. Ashdown \& K. Boviar (eds.) Enabling Access: Effective Teaching and Learning for Pupils with Learning Difficulties. London: David Fulton

Rose, R. (1998) 'The curriculum: a vehicle for inclusion or a lever for exclusion?', in C. Tilstone, L. Florian and R. Rose (eds.) Promoting Inclusive Practice: London: Routledge.

Sebba, J., Byers, R. \& Rose, R. (1993) Redefining the Whole Curriculum for People with Learning Difficulties. London: David Fulton.

Starkey, P. and Gelman, R. (1982) 'Addition and Subtraction Algorithm in pre-school children'. In T. Rombverg,.., T. Carpenter, and J. Moser, (eds.) Additional and Subtraction: A developmental perspective. Hillsdale, NJ.: Lawrence Erlbaum. 